\title{
Diagnostic Performance of Office versus Ambulatory Blood Pressure in Kidney Transplant Recipients
}

\author{
Maria Korogiannou ${ }^{a}$ Pantelis Sarafidis $^{b}$ Marieta P. Theodorakopoulou ${ }^{b}$ \\ Maria-Eleni Alexandrou ${ }^{b}$ Efstathios Xagas $^{a}$ Ioannis N. Boletis ${ }^{a}$ \\ Smaragdi Marinaki ${ }^{a}$
}

${ }^{a}$ Clinic of Nephrology and Renal Transplantation, Laiko General Hospital, Medical School of Athens, National and Kapodistrian University, Athens, Greece; bepartment of Nephrology, Hippokration Hospital, Aristotle University of Thessaloniki, Thessaloniki, Greece

\section{Keywords}

Kidney transplantation $\cdot$ Office blood pressure $\cdot$ Ambulatory blood pressure $\cdot$ Prevalence $\cdot$ Control

\begin{abstract}
Introduction: Hypertension is the most prominent risk factor in kidney transplant recipients (KTRs). No study so far assessed in parallel the prevalence, control, and phenotypes of blood pressure (BP) or the accuracy of currently recommended office BP diagnostic thresholds in diagnosing elevated ambulatory BP in KTRs. Methods: 205 stable KTRs underwent office BP measurements and 24-h ambulatory BP monitoring (ABPM). Hypertension was defined as follows: (1) office BP $\geq 140 / 90 \mathrm{~mm} \mathrm{Hg}$ or use of antihypertensive agents following the current European Society of Cardiology/European Society of Hypertension (ESC/ESH) guidelines, (2) office BP $\geq 130 / 80 \mathrm{~mm} \mathrm{Hg}$ or use of antihypertensive agents following the current American College of Cardiology/American Heart Association (ACC/AHA) guidelines, (3) ABPM $\geq 130 / 80 \mathrm{~mm} \mathrm{Hg}$ or use of antihypertensive agents, and (4) ABPM $\geq 125 / 75 \mathrm{~mm}$ $\mathrm{Hg}$ or use of antihypertensive agents. Results: Hypertension prevalence by office BP was $88.3 \%$ with ESC/ESH and $92.7 \%$
\end{abstract} \\ Karger'}

with ACC/AHA definitions compared to 94.1 and $98.5 \%$ at relevant ABPM thresholds. Control rates among hypertensive patients were 69.6 and $43.7 \%$ with office BP compared to 38.3 and $21.3 \%$ with $A B P M$, respectively. Both for prevalence ( $\mathrm{K}$-statistics $=0.52, p<0.001$ and 0.32 , and $p<0.001$ ) and control rates $(\mathrm{k}$-statistics $=0.21, p<0.001$ and 0.22 , and $p<0.001$, respectively), there was moderate or fair agreement of the 2 techniques. White-coat and masked hypertension were diagnosed in 6.7 and $39.5 \%$ of patients at the 140/90 threshold and 5.9 and $31.7 \%$ of patients at the $130 / 80$ threshold. An office $B P \geq 140 / 90 \mathrm{~mm} \mathrm{Hg}$ had $35.3 \%$ sensitivity and $84.9 \%$ specificity for the diagnosis of $24-\mathrm{h} B P \geq 130 / 80 \mathrm{~mm} \mathrm{Hg}$. An office BP $\geq 130 / 80 \mathrm{~mm} \mathrm{Hg}$ had $59.7 \%$ sensitivity and $73.9 \%$ specificity for the diagnosis of $24-\mathrm{h} \mathrm{BP} \geq 125 / 75 \mathrm{~mm} \mathrm{Hg}$. Receiver operating curve analyses confirmed this poor diagnostic performance. Conclusions: At both corresponding thresholds studied, ABPM revealed particularly high hypertension prevalence and poor BP control in KTRs. Misclassification of KTRs by office BP is substantial, due to particularly high rates of masked hypertension. The diagnostic accuracy of office BP for identifying elevated ambulatory BP is poor. These findings call for a wider use of ABPM in KTRs.

(c) 2021 S. Karger AG, Basel
Correspondence to:

Pantelis Sarafidis, psarafidis11@yahoo.gr 


\section{Introduction}

Chronic kidney disease (CKD) is a major public health problem; its prevalence is estimated at $10-15 \%$ of the adult population across the world [1]. Hypertension is the most common comorbidity in patients with CKD, with a reported overall prevalence of $>80 \%$ (i.e., about $2.5-3$ times higher than that in the general population) and a gradual increase with advancing CKD stages [2].

Kidney transplantation is the renal replacement modality of choice for patients with end-stage kidney disease (ESKD). Successful kidney transplantation is associated with improved survival and quality of life compared to dialysis, mainly attributed to restoration of renal function that halts the progression of cardiovascular disease [3]. However, the risk of cardiovascular death in transplanted patients remains significantly higher than that in the general population [4]; furthermore, although there has been a downtrend in mortality of kidney transplant recipients (KTRs) over the past 2 decades, a substantial percentage of KTRs die in 10 years with a functioning graft, and cardiovascular disease remains the leading cause of death [5]. Hypertension is the most prominent risk factor for cardiovascular disease in KTRs; it has a high prevalence (70-95\%) [6] and is associated with both poor graft and patient survival [7].

The diagnosis and management of hypertension in KTRs was traditionally based on blood pressure (BP) measurements in the office setting. However, office BP has several limitations in diagnosing hypertension compared to the golden standard of BP measurement, 24-h ambulatory BP monitoring (ABPM). The use of ABPM enables identification of white-coat and masked hypertension, the latter being particularly important, given its association with target-organ damage and cardiovascular events. In addition, ABPM is the only method that enables assessment of diurnal BP patterns $[8,9]$. To this end, pilot studies in KTRs suggest a particularly high rate of masked hypertension, at about $35-40 \%[10,11]$. Furthermore, several studies have shown that disrupted circadian BP patterns are common in KTRs and are associated with markers of vascular damage, cardiovascular events, and poor graft survival [12-14].

The optimal office BP threshold to diagnose hypertension and the relevant target in patients with CKD in general, as well as KTRs in particular is still a matter of intense debate [15]. In 2014, the Joint National Committee (JNC) 8 guidelines suggested a BP threshold of 140/90 and a target of $<140 / 90 \mathrm{~mm} \mathrm{Hg}$ for patients with CKD [16], while currently, there is a discrepancy between the
2018 European Society of Hypertension/European Society of Cardiology (ESH/ESC) guidelines [17] suggesting a threshold of $140 / 90 \mathrm{~mm} \mathrm{Hg}$ and a systolic blood pressure (SBP) target between 130 and $139 \mathrm{~mm} \mathrm{Hg}$, and the 2017 American College of Cardiology/American Heart Association (ACC/AHA) guidelines [18] that introduced a BP threshold of $130 / 80 \mathrm{~mm} \mathrm{Hg}$ in all patients, including those with CKD. Importantly, the latter guidelines first proposed with a distinct referral this target also for KTRs. Recently, the 2021 Kidney Disease: Improving Global Outcomes (KDIGO) guidelines also suggest a target of $<130 / 80 \mathrm{~mm} \mathrm{Hg}$ in KTRs and recommend a wider use of $\mathrm{ABPM}$ in CKD and in transplant patients but offer no threshold for BP diagnosis in these individuals [19].

In light of the above, we conducted a cross-sectional study in a large cohort of KTRs in order to identify the following: (a) the rates of prevalence, treatment, and control of hypertension with the use of office BP with the 2 existing definitions and relevant ABPM thresholds; (b) the proportions of patients having white-coat or masked hypertension; and (c) the diagnostic performance of the ESC/ESH and ACC/AHA BP thresholds to identify 24-h elevated BP.

\section{Subjects and Methods}

\section{Study Population}

This is a cross-sectional study in adult, stable KTRs under regular follow-up at the Renal Transplantation Outpatient Clinic of the Department of Nephrology, Laiko General Hospital, Greece. The inclusion criteria were (a) age $>18$ years and (b) $\geq 6$ months from kidney transplant surgery. Exclusion criteria consisted of the following criteria: (a) an estimated glomerular filtration rate $<20$ $\mathrm{mL} / \mathrm{min} / 1.73 \mathrm{~m}^{2}$; (b) an estimated glomerular filtration rate decline $>30 \%$ during the last 3 months; (c) chronic atrial fibrillation or other arrhythmias that interfered with execution of a proper ABPM recording; (d) presence of bilateral arteriovenous fistulae that could interfere with proper ABPM recording; (e) change in antihypertensive treatment during the last 6 weeks; (f) myocardial infarction or stroke during the last 3 months; (g) history of malignancy or any other condition with poor prognosis; and (h) pregnancy. The study protocol was approved by the Institutional Review Board of Laiko General Hospital. All evaluations were performed according to the Declaration of Helsinki (2013 Amendment). Written informed consent was obtained from each included participant.

\section{Data Acquisition and ABPM}

All patients were evaluated during a scheduled morning visit. Data for each subject were recorded on specific forms and were transferred to a purpose-built electronic data-collecting sheet. We collected information on demographics, height, and weight for the calculation of body mass index, cause of ESKD, previous dialysis vintage, comorbidities, routine hematological and biochemical pa- 
Table 1. Baseline characteristics of the study participants

\begin{tabular}{|c|c|}
\hline \multicolumn{2}{|l|}{ Parameter } \\
\hline$N$ & 205 \\
\hline Age, years & $51.7 \pm 12.9$ \\
\hline Male, $n(\%)$ & $136(66.3)$ \\
\hline Time from transplantation surgery, months & $75.7[133.5]$ \\
\hline Previous dialysis vintage, months & $32.0[62.0]$ \\
\hline BMI, $\mathrm{kg} / \mathrm{m}^{2}$ & $26.8 \pm 11.8$ \\
\hline \multicolumn{2}{|l|}{ Primary cause of ESKD, $n(\%)$} \\
\hline Diabetes mellitus & $7(3.4)$ \\
\hline Hypertension & $8(3.9)$ \\
\hline Glomerulonephritis & $75(36.6)$ \\
\hline ADPKD & $29(14.1)$ \\
\hline Obstructive & $21(10.2)$ \\
\hline Other & $12(5.9)$ \\
\hline Unknown & $53(25.9)$ \\
\hline Diabetes mellitus, $n(\%)$ & $36(17.6)$ \\
\hline Coronary heart disease, $n(\%)$ & $20(9.8)$ \\
\hline Peripheral arterial disease, $n(\%)$ & $6(2.9)$ \\
\hline Stroke, $n(\%)$ & $2(1.0)$ \\
\hline Dyslipidemia, $n(\%)$ & $107(52.2)$ \\
\hline Smokers, $n(\%)$ & $19(9.3)$ \\
\hline $\mathrm{eGFR}, \mathrm{mL} / \mathrm{min} / 1.73 \mathrm{~m}^{2}$ & $57.9 \pm 19.5$ \\
\hline Hemoglobin, g/dL & $13.0 \pm 1.6$ \\
\hline Uric acid, mg/dL & $6.7 \pm 1.4$ \\
\hline Urea, $\mathrm{mg} / \mathrm{dL}$ & $60.0 \pm 27.4$ \\
\hline Creatinine, $\mathrm{mg} / \mathrm{dL}$ & $1.4 \pm 0.5$ \\
\hline Sodium, mg/dL & $140.4 \pm 2.8$ \\
\hline Potassium, mg/dL & $4.5 \pm 0.5$ \\
\hline Calcium, mg/dL & $9.6 \pm 0.5$ \\
\hline Phosphorus, mg/dL & $3.1 \pm 0.7$ \\
\hline \multicolumn{2}{|l|}{ Immunosuppressive medication, $n(\%)$} \\
\hline Cyclosporine & $28(13.7)$ \\
\hline Tacrolimus & $166(81.0)$ \\
\hline mTOR inhibitors & $19(9.3)$ \\
\hline MMF/MPA & $189(92.2)$ \\
\hline Azathioprine & $3(1.5)$ \\
\hline Corticosteroids & $167(81.5)$ \\
\hline Other & $1(0.5)$ \\
\hline Antihypertensive medication, $n(\%)$ & $175(85.4)$ \\
\hline ACEi/ARBs, $n(\%)$ & $85(41.5)$ \\
\hline CCBs, $n(\%)$ & $84(41.0)$ \\
\hline$\beta$-Blocker, $n(\%)$ & $137(66.8)$ \\
\hline a-Blocker, $n(\%)$ & $2(1.0)$ \\
\hline Centrally active agents, $n(\%)$ & $16(7.8)$ \\
\hline Diuretics, $n(\%)$ & $22(10.7)$ \\
\hline \multicolumn{2}{|l|}{ Antihypertensive medications, $n(\%)$} \\
\hline 1 agent & $60(29.3)$ \\
\hline 2 agents & $72(35.1)$ \\
\hline 3 agents & $30(14.6)$ \\
\hline$\geq 4$ agents & $13(6.3)$ \\
\hline Office SBP, mm Hg & $129.0 \pm 16.9$ \\
\hline Office DBP, mm Hg & $76.5 \pm 10.2$ \\
\hline 24-h SBP, mm Hg & $126.5 \pm 12.0$ \\
\hline 24-h DBP, mm Hg & $81.2 \pm 8.4$ \\
\hline Daytime SBP, mm Hg & $127.2 \pm 12.1$ \\
\hline Daytime DBP, mm Hg & $82.1 \pm 8.6$ \\
\hline Nighttime SBP, mm Hg & $123.9 \pm 14.5$ \\
\hline Nighttime DBP, mm Hg & $77.7 \pm 19.2$ \\
\hline
\end{tabular}

$\mathrm{ACEi}$, angiotensin-converting enzyme inhibitors; ARBs, angiotensin receptor blockers; BMI, body mass index; $\mathrm{CCBs}$, calcium-channel blockers; DBP, diastolic blood pressure; eGFR, estimated glomerular filtration rate; ESKD, end-stage kidney disease; MMF, mycophenolate mofetil; MPA, mycophenolic acid; SBP, systolic blood pressure; rameters, and transplantation-related parameters for each participant. Office BP was measured at the level of brachial artery following at least $5 \mathrm{~min}$ of rest using a validated oscillometric device and a cuff of appropriate size, according to recommendations [17]. Three $\mathrm{BP}$ readings were taken with 1-min intervals, and their average was used in the analysis.

ABPM was performed with the Mobil-O-Graph device (IEM, Stolberg, Germany), a validated oscillometric device [20,21], that was previously shown to provide practically identical values with a widely used ABPM monitor [22]. The device was fitted on the nonfistula arm with a cuff of appropriate size and measured BP every 15 min during daytime and every 30 min during nighttime. Patients were instructed to follow their usual activities. Measurements were used for the analysis if $>70 \%$ of recordings were valid with $\leq 2$ nonconsecutive day-hours with $<2$ valid measurements, and $\leq 1$ night-hour without valid recording for each 24 -h period [23]. In case of invalid measurements, patients were invited to undertake the ABPM again. To minimize the possible effect of manual BP measurements, only measurements recorded at the prespecified time intervals at which the device was set to take measurements were used in this analysis.

The flowchart of study participants is presented in online suppl. Figure 1 at www.karger.com/doi/10.1159/000517358. Two hundred twenty-two KTRs fulfilled the aforementioned inclusion and exclusion criteria and consented to participate. Of these, 20 patients had invalid 24-h ABPM recordings at the first instance. Five of them accepted to repeat the ABPM, of which 2 had again invalid recordings and refused further testing. Thus, a total of 205 patients represented the final study population.

\section{Definitions}

Hypertension was defined in the following ways: (a) an office $\mathrm{BP} \geq 140 / 90 \mathrm{~mm} \mathrm{Hg}$ or current use of antihypertensive medication, following the recent ESC/ESH guidelines [17]; (b) an office BP $\geq 130 / 80 \mathrm{~mm} \mathrm{Hg}$ or current use of antihypertensive medication, following the recent ACC/AHA guidelines [18]; (c) an ambulatory 24-h BP $\geq 130 / 80 \mathrm{~mm} \mathrm{Hg}$ or current use of antihypertensive medication; (d) an ambulatory $24-\mathrm{h} \mathrm{BP} \geq 125 / 75 \mathrm{~mm} \mathrm{Hg}$; or current use of antihypertensive medication. The two 24-BP thresholds are those corresponding to the 2 office BP thresholds, according to ACC/AHA guidelines [18]. We defined "hypertension treatment" as the proportion of hypertensive patients receiving at least one antihypertensive drug. We defined "hypertension control" as the proportion of hypertensive patients achieving an office $\mathrm{BP}<140 / 90$ or $<130 / 80 \mathrm{~mm} \mathrm{Hg}$, or $24-\mathrm{h} \mathrm{BP}<130 / 80$ or $<125 / 75 \mathrm{~mm} \mathrm{Hg}$, depending on the definition used.

In addition to the above, we established phenotypes of hypertension control using a 4-group categorization of hypertensive patients as follows: (a) "concordant control," defined as an office $\mathrm{BP}<140 / 90 \mathrm{~mm} \mathrm{Hg}$ (or $<130 / 80 \mathrm{~mm} \mathrm{Hg}$ following the ACC/ AHA guidelines) and ABPM $<130 / 80 \mathrm{~mm} \mathrm{Hg}$ (or $<125 / 75 \mathrm{~mm}$ $\mathrm{Hg}$, respectively); (b) "concordant lack of control," defined as an office BP $\geq 140 / 90 \mathrm{~mm} \mathrm{Hg}$ or $(\geq 130 / 80 \mathrm{~mm} \mathrm{Hg})$ and ABPM $\geq 130 / 80 \mathrm{~mm} \mathrm{Hg}$ (or $\geq 125 / 75 \mathrm{~mm} \mathrm{Hg}$ ); (c) white-coat hypertension, defined as an office BP $\geq 140 / 90 \mathrm{~mm} \mathrm{Hg}$ (or $\geq 130 / 80 \mathrm{~mm}$ $\mathrm{Hg}$ ) and $\mathrm{ABPM}<130 / 80 \mathrm{~mm} \mathrm{Hg}$ (or $<125 / 75 \mathrm{~mm} \mathrm{Hg}$ ); and (d) masked hypertension, defined an as office $\mathrm{BP}<140 / 90 \mathrm{~mm} \mathrm{Hg}$ (or $<130 / 80 \mathrm{~mm} \mathrm{Hg}$ ) and ABPM $\geq 130 / 80 \mathrm{~mm} \mathrm{Hg}$ (or $\geq 125 /$ $75 \mathrm{~mm} \mathrm{Hg})$. 
Table 2. Prevalence, treatment, and control of hypertension according to the 3 different definitions

\begin{tabular}{|c|c|c|c|c|}
\hline & $\begin{array}{l}\text { ESC/ESH office } \\
\mathrm{BP} \geq 140 / 90 \mathrm{~mm} \mathrm{Hg} \\
\text { or antihypertensive } \\
\text { treatment }\end{array}$ & $\begin{array}{l}\mathrm{ABPM} 24 \mathrm{~h} \\
\mathrm{BP} \geq 130 / 80 \mathrm{~mm} \mathrm{Hg} \\
\text { or antihypertensive } \\
\text { treatment }\end{array}$ & $\begin{array}{l}\text { ACC/AHA office } \\
\mathrm{BP} \geq 130 / 80 \mathrm{~mm} \mathrm{Hg} \\
\text { or antihypertensive } \\
\text { treatment }\end{array}$ & $\begin{array}{l}\text { ABPM } 24 \mathrm{~h} \\
\mathrm{BP} \geq 125 / 75 \mathrm{~mm} \mathrm{Hg} \\
\text { or antihypertensive } \\
\text { treatment }\end{array}$ \\
\hline Prevalence, $n(\%)$ & $181(88.3)$ & $193(94.1)$ & $190(92.7)$ & $202(98.5)$ \\
\hline BP levels above threshold, $n(\%)$ & $55(30.4)$ & $119(61.7)$ & $107(56.3)$ & $159(78.7)$ \\
\hline Hypertensive patients on treatment, $n(\%)$ & $175(96.7)$ & $175(90.7)$ & $175(92.1)$ & $175(86.6)$ \\
\hline
\end{tabular}

BP, blood pressure; ABPM, ambulatory blood pressure monitoring; ESC/ESH, European Society of Cardiology/European Society of Hypertension; ACC/AHA, American College of Cardiology/American Heart Association.

\section{Statistical Analysis}

Statistical analysis was performed with Statistical Package for Social Sciences version 23.0 (SPSS Inc., Chicago, IL, USA). The normality of distribution for quantitative variables was examined using the Kolmogorov-Smirnov test. Continuous variables are presented as mean \pm standard deviation or median (interquartile range), according to the normality of distribution. Categorical variables are presented as absolute frequencies and percentages $(n$, $\%)$. Concordance between the different definitions for hypertension was assessed using $\mathrm{k}$-statistic (strength of agreement: poor, 0 to $\leq 0.20$; fair, 0.21 to $\leq 0.40$; moderate, 0.41 to $\leq 0.60$; good, 0.61 to $\leq 0.80$; and very good, 0.81 to $\leq 1.00)$ [24]. The ability of the 2 different thresholds of office BP ( $\geq 140 / 90$ and $\geq 130 / 80 \mathrm{~mm} \mathrm{Hg}$ ) to diagnose hypertension as assessed by 24 -h ABPM was tested by calculating the sensitivity, specificity, positive predictive value (PPV), and negative predictive value (NPV), as well as by analyzing the area under relevant receiver operating curves (ROCs). In addition, we performed ROC analysis of office SBP/diastolic blood pressure (DBP) examined as a continuous variable for the diagnosis of a $24-\mathrm{h} \mathrm{SBP} \geq 130 \mathrm{~mm} \mathrm{Hg}$ and $\mathrm{DBP} \geq 80 \mathrm{~mm} \mathrm{Hg}$, respectively; the optimal cutoff point for BP was assessed based on the Youden Index, calculated as follows: sensitivity + specificity -1 . The higher the index, the better is the classification at the cutoff point. Probability values of $p<0.05$ (two-tailed) were considered statistically significant.

\section{Results}

Demographic and Clinical Characteristics of the Study Population

Table 1 presents baseline demographics, clinical and laboratory characteristics, antihypertensive agents, and mean BP levels of the study population. A total of 205 KTRs (136 males) with a mean age of $51.7 \pm 12.9$ years and a median time from transplantation surgery of 75.7 [133.5] months were included in the analysis. Beyond hypertension, dyslipidemia (52.2\%), and diabetes mellitus $(17.6 \%)$ were the most common comorbidities. The mean office SBP/DBP was $129.0 \pm 16.9 / 76.5 \pm 10.2 \mathrm{~mm} \mathrm{Hg}$, mean 24-h BP $126.5 \pm 12.0 / 81.2 \pm 8.4 \mathrm{~mm} \mathrm{Hg}$, mean daytime BP $127.2 \pm 12.1 / 82.1 \pm 8.6 \mathrm{~mm} \mathrm{Hg}$, and mean nighttime BP $123.9 \pm 14.5 / 77.7 \pm 19.2 \mathrm{~mm} \mathrm{Hg}$ (Table 1).

\section{Prevalence, Treatment, and Control of Hypertension}

The proportions of prevalence, treatment, and control of hypertension according to the definitions used are presented in Table 2. The prevalence of hypertension by the $\mathrm{ESC} / \mathrm{ESH}$ definition (office BP $\geq 140 / 90 \mathrm{~mm} \mathrm{Hg}$ or antihypertensive treatment) was $88.3 \%$, by ACC/AHA definition (office $\mathrm{BP} \geq 130 / 80 \mathrm{~mm} \mathrm{Hg}$ or antihypertensive treatment) was $92.7 \%$, and by ABPM was $94.1 \%$ and as much as $98.5 \%$ at the $24-\mathrm{h} \mathrm{BP} \geq 130 / 80$ and $125 / 75 \mathrm{~mm} \mathrm{Hg}$ thresholds, respectively. Following the different prevalence rate differences between relevant office and ABPM definitions, the agreement between office and ABPM methods was only moderate or fair ( $\kappa$-statistic $=0.52, p<$ 0.001 for $\mathrm{ESC} / \mathrm{ESH}$ thresholds and $\kappa$-statistics $=0.32, p<$ 0.001 for ACC/AHA thresholds). A total of 175 patients were receiving antihypertensive treatment, generating slightly different proportions of treatment with the various definitions. Thus, from the total population, $14.7 \%$ of patients were receiving no antihypertensive treatment and $29.3,35.1,14.6$, and $6.3 \%$ were receiving $1,2,3$, or $\geq 4$ antihypertensive agents, respectively. The rates of control among patients with hypertension were $69.6 \%$ at the $<140 / 90 \mathrm{~mm} \mathrm{Hg}$ office threshold but only $38.3 \%$ at the $<130 / 80 \mathrm{~mm} \mathrm{Hg} 24$-h BP threshold, as well as $43.7 \%$ at the $<130 / 80 \mathrm{~mm} \mathrm{Hg}$ office and as low as $21.3 \%$ at the $<125 / 75 \mathrm{~mm} \mathrm{Hg} 24-\mathrm{h}$ BP threshold. The relevant $\kappa$-statistic values were $0.21(p<0.001)$ for the ESC/ESH and $0.22(p<0.001)$ for the ACC/AHA definition in relation to the $\mathrm{ABPM}$ control rate. Among patients receiving treatment with a single antihypertensive agent, there was 
Fig. 1. Phenotypes of BP control based on different office BP thresholds and 24-h ABPM office BP $\geq 140 / 90 \mathrm{~mm} \mathrm{Hg}$ according to $\mathrm{ESC} / \mathrm{ESH}$ guidelines and $\mathrm{ABPM}$ $\geq 130 / 80 \mathrm{~mm} \mathrm{Hg}$ (a) office $\mathrm{BP} \geq 130 / 80 \mathrm{~mm}$ $\mathrm{Hg}$ according to ACC/AHA guidelines and ABPM $\geq 125 / 75 \mathrm{~mm} \mathrm{Hg}$ (b). BP, blood pressure; ABPM, ambulatory blood pressure monitoring; ESC/ESH, European Society of Cardiology/European Society of Hypertension; ACC/AHA, American College of Cardiology/American Heart Association.

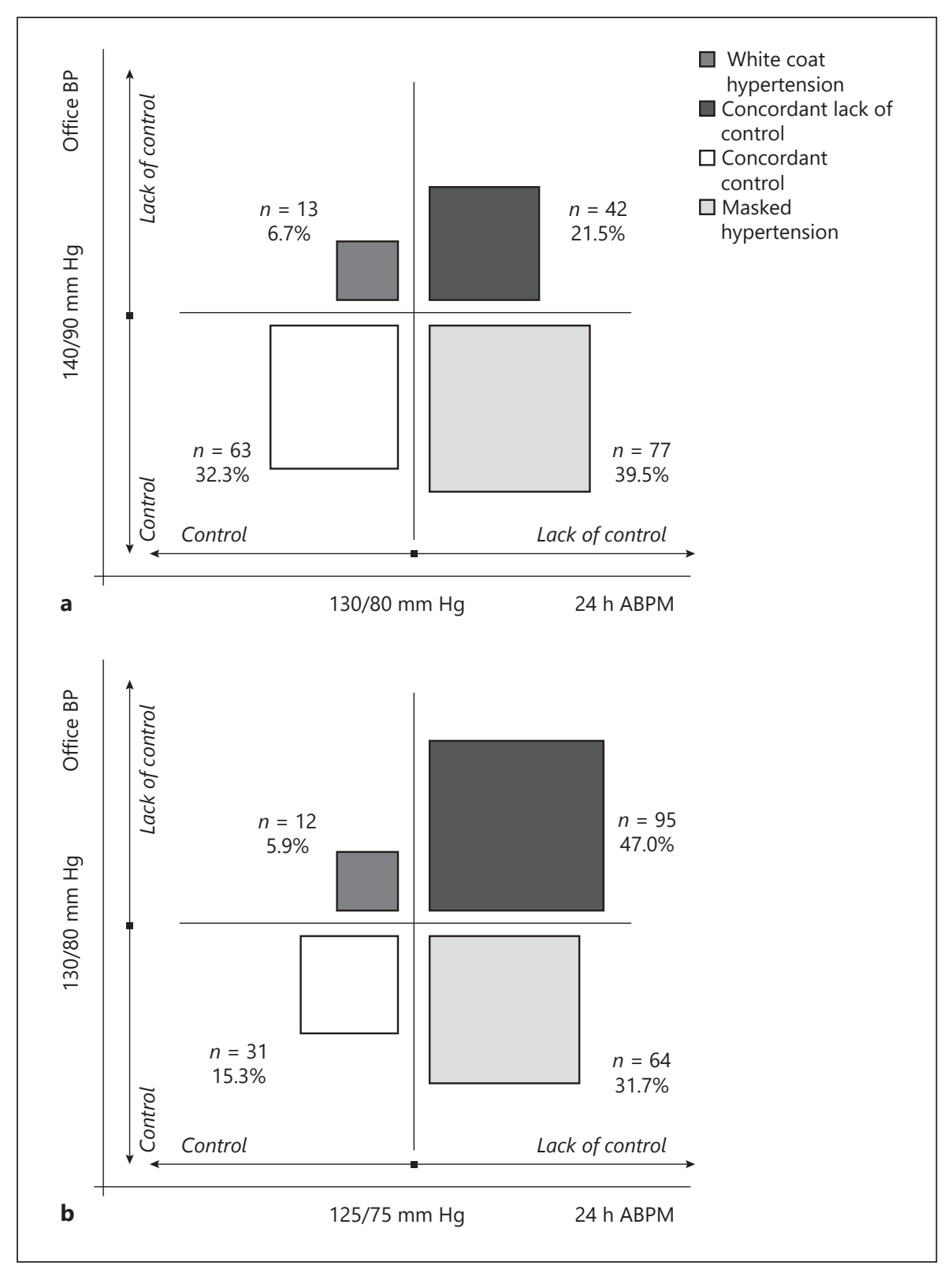

no difference in the control rate between those receiving an ACEi/ARB, a CCB, or a $\beta$-blocker at any of the thresholds studied (e.g., at the $<130 / 80 \mathrm{~mm} \mathrm{Hg} 24$-h threshold, control rates of $44.4,42.9$, and $42.9 \%$, respectively, $p=$ 0.994).

Concordance of BP Control, White-Coat, and Masked Hypertension

With the use of ESC/ESH office definition and ABPM, 10 participants $(4.9 \%)$ were classified as having normal office and 24-h BP levels, while the rest 195 participants
(95.1\%) were classified as having hypertension with at least one of the 2 methods. As shown in Figure 1a, 32.3\% of patients had concordant control by office and ABP readings, and $21.5 \%$ had concordant lack of control. White-coat hypertension was diagnosed in $6.7 \%$ of patients, and masked hypertension was diagnosed in $39.5 \%$ of patients, that is, in 77 of 195 KTRs identified with hypertension.

In addition to the above, with the use of ACC/AHA office definition and ABPM, only 3 KTRs (1.5\%) were classified as having normal office and 24-h BP levels; the 


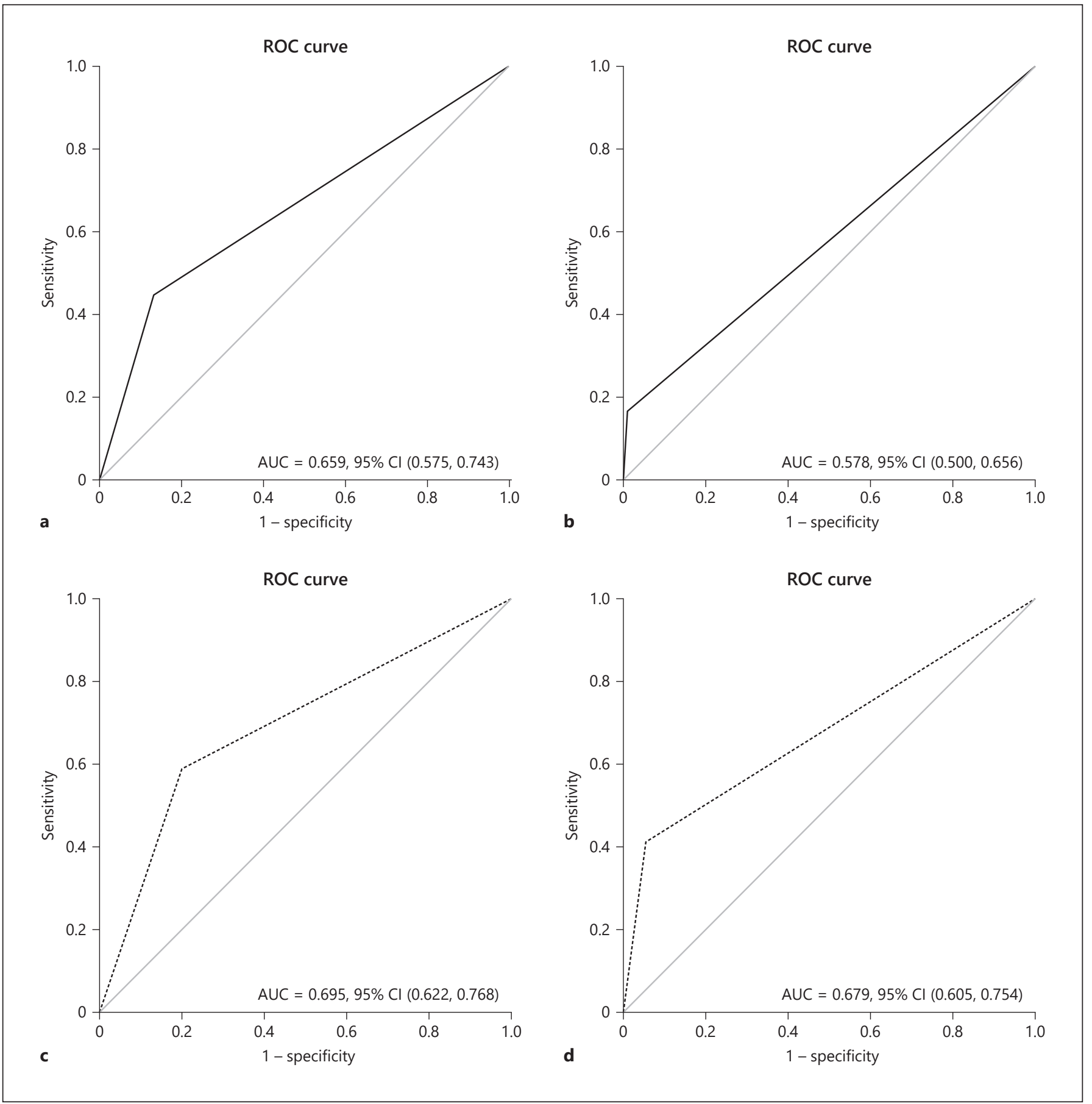

Fig. 2. ROC curves on the ability of office $S B P \geq 140$ or $\geq 130 \mathrm{~mm}$ $\mathrm{Hg}$ according to ESC/ESH and ACC/AHA guidelines, respectively, for diagnosing 24-h SBP $\geq 130$ or $125 \mathrm{~mm} \mathrm{Hg}$, respectively (a, c); office DBP $\geq 90$ or $\geq 80 \mathrm{~mm} \mathrm{Hg}$ according to ESC/ESH and ACC/ AHA guidelines, respectively, for diagnosing $24-\mathrm{h} \mathrm{DBP} \geq 80$ or $\geq 75$

$\mathrm{mm} \mathrm{Hg}$, respectively (b, d). ROC, receiver-operating curve; DBP, diastolic blood pressure; SBP, systolic blood pressure; ESC/ESH, European Society of Cardiology/European Society of Hypertension; ACC/AHA, American College of Cardiology/American Heart Association. 
Table 3. Sensitivity, specificity, positive predictive value, and negative predictive value for the different office $\mathrm{BP}$ thresholds (ESC/ESH office BP $\geq 140 / 90 \mathrm{~mm} \mathrm{Hg}$ and ACC/AHA office BP $\geq 130 / 80 \mathrm{~mm} \mathrm{Hg}$ ) in diagnosing 24-h $\mathrm{BP} \geq 130 / 80$ and $\geq 125 / 75 \mathrm{~mm} \mathrm{Hg}$, respectively

\begin{tabular}{lllll}
\hline & $\begin{array}{l}\text { Sensitivity, } \\
\%\end{array}$ & $\begin{array}{l}\text { Specificity, } \\
\%\end{array}$ & $\begin{array}{l}\text { Positive predictive } \\
\text { value, } \%\end{array}$ & $\begin{array}{l}\text { Negative predictive } \\
\text { value, } \%\end{array}$ \\
\hline ESC/ESH office BP $\geq 140 / 90 \mathrm{~mm} \mathrm{Hg}$ & 35.3 & 84.9 & 76.4 & 48.7 \\
ACC/AHA office BP $\geq 130 / 80 \mathrm{~mm} \mathrm{Hg}$ & 59.7 & 73.9 & 88.8 & 34.7 \\
\hline
\end{tabular}

BP, blood pressure; ESC/ESH, European Society of Cardiology/European Society of Hypertension; ACC/ AHA, American College of Cardiology/American Heart Association.

rest 202 participants (98.5\%) were classified as having hypertension with at least one of the 2 methods. As depicted in Figure 1b, $15.3 \%$ of patients had concordant control by office and ABPM readings, while $47 \%$ had concordant lack of control. White-coat hypertension was diagnosed in $5.9 \%$ of patients, and masked hypertension was diagnosed in $31.7 \%$ of patients, that is, in 64 of 202 KTRs identified with hypertension.

\section{Diagnostic Performance of Office Hypertension}

Definitions in Relation to ABPM Definition

Table 3 presents the sensitivity, specificity, PPV, and NPV of office BP at the 140/90 and 130/80 $\mathrm{mm} \mathrm{Hg}$ thresholds in diagnosing 24-h SBP/DBP $\geq 130 / 80$ and $\geq 125 / 75$ $\mathrm{mm} \mathrm{Hg}$. An office BP $\geq 140 / 90 \mathrm{~mm} \mathrm{Hg}$ had very low sensitivity (35.3\%) and acceptable specificity ( $84.9 \%)$, corresponding to acceptable PPV (76.4\%) and very low NPV (48.7\%) for the diagnosis of $24-\mathrm{h} \mathrm{SBP} / \mathrm{DBP} \geq 130 / 80 \mathrm{~mm}$ $\mathrm{Hg}$. In addition, an office $\mathrm{BP} \geq 130 / 80 \mathrm{~mm} \mathrm{Hg}$ had somehow better but again suboptimal performance with moderate sensitivity (59.7\%) and specificity (73.9\%), PPV (88.8\%), and NPV (34.7\%) for the diagnosis of $24-\mathrm{h} \mathrm{SBP/}$ $\mathrm{DBP} \geq 125 / 75 \mathrm{~mm} \mathrm{Hg}$. Accordingly, the AUCs of the office SBP/DBP with the ESC/ESH definition for the diagnosis $24-\mathrm{h} \mathrm{SBP} / \mathrm{DBP} \geq 130 / 80 \mathrm{~mm} \mathrm{Hg}$ were 0.659 (95\% confidence interval $[\mathrm{CI}] 0.575,0.743)$ and 0.578 (95\% CI $0.500,0.656)$, respectively, indicating in general a poor diagnostic performance (Fig. 2a, b). The relevant AUCs with the ACC/AHA definition were slightly higher, that is, 0.695 (95\% CI 0.622, 0.768) and 0.679 (95\% CI 0.605, 0.754), respectively, for SBP/DBP (Fig. 2c, d).

Figure 3 presents ROC analyses for office $\mathrm{BP}$ examined as a continuous variable for the diagnosis of a 24-h SBP $\geq 130 \mathrm{~mm} \mathrm{Hg}$ and $\mathrm{DBP} \geq 80 \mathrm{~mm} \mathrm{Hg}$. The ROC curve for office SBP showed an AUC at 0.779 (95\% CI [0.711, $0.847]$ ) and a sensitivity of $67.2 \%$ and a specificity of $76.1 \%$ (Youden index 0.433 ), with an optimal cutoff at
$130.50 \mathrm{~mm} \mathrm{Hg}$ in diagnosing a 24-h SBP $\geq 130 \mathrm{~mm} \mathrm{Hg}$. AUC for the office DBP was 0.768 (95\% CI [0.703, 0.833]), with a $75.5 \mathrm{~mm} \mathrm{Hg}$ cutoff for an optimal Youden Index at 0.444 (sensitivity $=72.2 \%$ and specificity $=72.2 \%$ ) in diagnosing a $24-\mathrm{h} \mathrm{DBP} \geq 80 \mathrm{~mm} \mathrm{Hg}$.

\section{Discussion}

This is the first study evaluating in parallel the rates of prevalence and control, the $\mathrm{BP}$ phenotypes, and the performance of 2 existing office BP thresholds in diagnosing high ambulatory BP in KTRs. The prevalence of hypertension by office BP definition was particularly high and became even higher with the golden standard method (24-h ABPM), reaching $98.5 \%$ of the total population at the 125/75 mm Hg ABPM threshold. Misclassification of patients by office BP occurred in a substantial proportion of the study population; this was mostly due to a particularly high prevalence of masked hypertension. As a result, the rates of control differed to a large extent between office and ABPM techniques at both corresponding thresholds examined, reaching a nadir $21.3 \%$ at the $125 / 75 \mathrm{~mm}$ $\mathrm{Hg}$ ABPM threshold. Finally, high office BP according to both ESC/ESH and ACC/AHA definitions was of particularly poor diagnostic value for identifying elevated $24-\mathrm{h}$ BP.

As already discussed, the optimal office BP threshold to diagnose hypertension and the relevant BP target in patients with CKD is currently still unclear, with different existing recommendations from major societies creating a confusing environment for the average practicing nephrologist [15]. This "chaos" of recommendations could be attributed to several reasons, including the absence of relevant evidence for specific types of CKD patients (such as those with diabetes), contrasting results during the randomized periods and the long-term observational ex- 


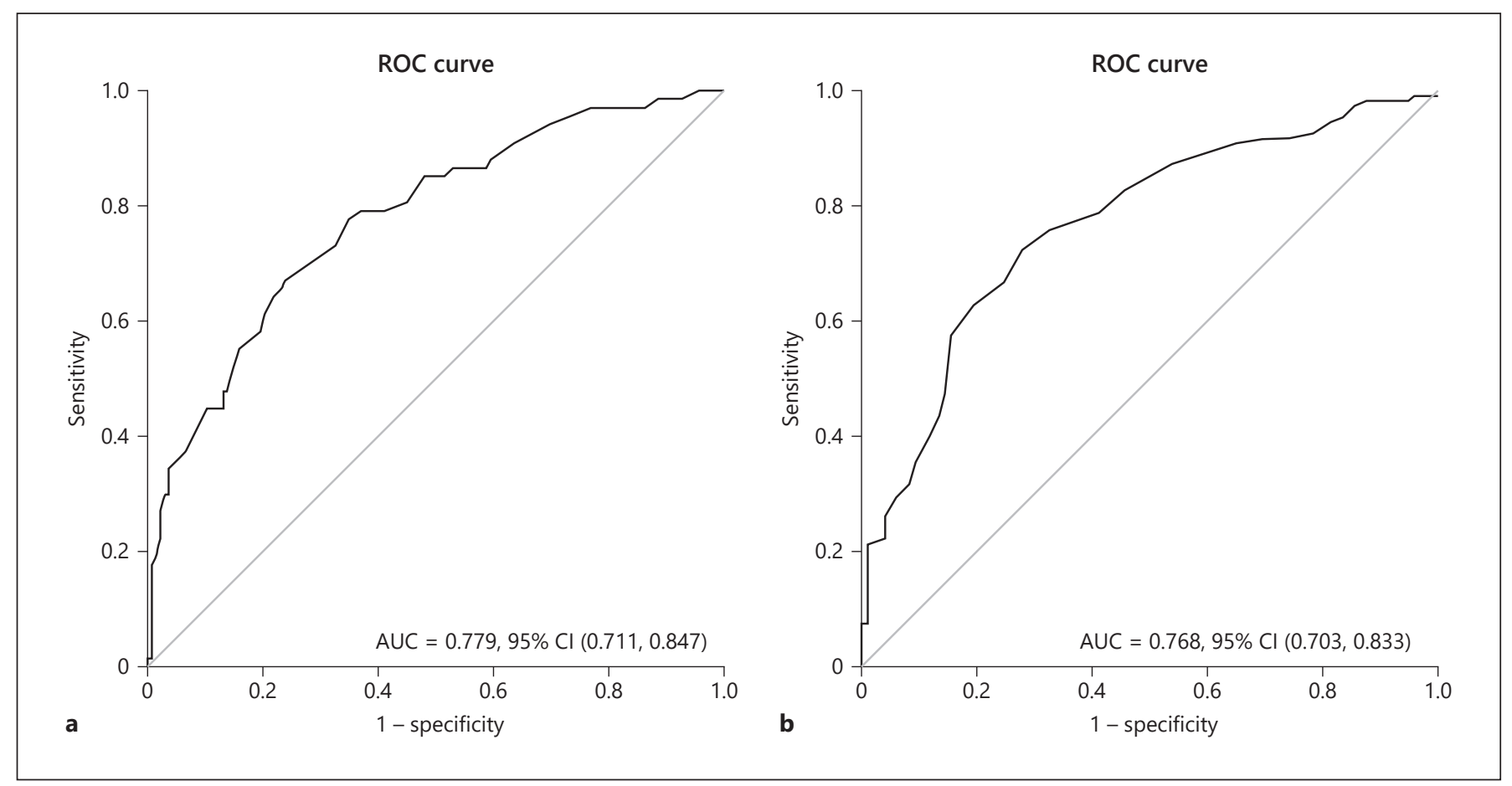

Fig. 3. ROC curves of office SBP in diagnosing 24-h SBP $\geq 130 \mathrm{~mm} \mathrm{Hg}$ (a) and office DBP in diagnosing 24-h $\mathrm{DBP} \geq 80 \mathrm{~mm} \mathrm{Hg}(\mathbf{b})$ in the whole population. ROC, receiver-operating curve; DBP, diastolic blood pressure; SBP, systolic blood pressure.

tensions of the few trials in the field, and the possibility that different BP targets have different effects on cardiovascular and renal outcomes [15,25-27]. With regard to KTRs, no specific guidance on these issues was offered by previous recommendation documents, probably due to the complete absence of evidence in this population. However, the 2017 ACC/AHA guidelines [18], which introduced a BP threshold of $130 / 80 \mathrm{~mm} \mathrm{Hg}$ and a target of $<130 / 80 \mathrm{~mm} \mathrm{Hg}$ in all patients, included KTRs in this recommendation, while the recent 2021 KDIGO BP guidelines [19] also specifically suggested a target BP $<130 / 80 \mathrm{~mm} \mathrm{Hg}$ in KTRs. Of note, both these documents advocated the wider use of ABPM in CKD and in transplant patients $[18,19]$. As such, relevant questions regarding the prevalence and control rates and the diagnostic performance of the $130 / 80 \mathrm{~mm} \mathrm{Hg}$ office threshold against the corresponding ABPM threshold clearly arise.

In the previous studies using the $140 / 90 \mathrm{~mm} \mathrm{Hg}$ hypertension office threshold, the prevalence of hypertension in KTRs varied considerably, ranging between 17 and $72 \%[12,28]$. In the few studies using the $130 / 80 \mathrm{~mm}$ $\mathrm{Hg}$ threshold, this rate was typically higher, between 22 and $95 \%[29,30]$. These large differences between the studies can be attributed to various factors, most impor- tantly the fact that the majority of studies define hypertension as BP above a certain threshold; such definitions do not list individuals with hypertension and successful control under antihypertensive treatment as hypertensives. Other factors that may contribute to different hypertension prevalence in KTR populations are differences between the studied cohorts with regards to age, race, cause of ESRD, dialysis vintage, quality of donor kidney (i.e., proportions of living vs. deceased donor), time from transplantation surgery, use of immunosuppressive drugs, and presence of comorbidities, such as obesity and diabetes [31, 32]. In recent years, studies that used ABPM reported hypertension prevalence between 24 [12] and $95 \%$ [30] at the 130/80 $\mathrm{mm} \mathrm{Hg}$ ambulatory threshold. Of note, in the only previous study that evaluated hypertension prevalence at both the $130 / 80 \mathrm{~mm} \mathrm{Hg}$ office and the corresponding 125/75 mm Hg ambulatory thresholds, Ahmed et al. [29] observed rates of 21.5 and 77\%, respectively in 98 KTRs. In a similar manner, control of hypertension in KTRs was shown to be around 40-60\% [33,34] with office and ABPM readings, whereas in the study of Ahmet et al. [29], the rate of concordant control at the low office and ambulatory thresholds was $20 \%$. Our study, using appropriate definitions, clarifies the above findings, 
showing higher prevalence and considerably lower control rates with the use of ABPM at both the corresponding thresholds studied.

One major advantage of ABPM use is revealing patients with white-coat and masked hypertension. Misclassification of patients with the use of office BP levels is a common phenomenon, both in the general population [23] and in patients with predialysis CKD [35] and with ESKD under hemodialysis [36]. Previous studies in KTRs revealed a unique phenomenon of very high rates of masked hypertension. In particular, 2 studies by Kayrak et al. [11] and Tiryaki et al. [10] in 113 and 116 patients showed masked hypertension at 39 and $36 \%$ of the population. Similarly, in a cross-sectional study including 92 stable KTRs, $36 \%$ of patients had masked hypertension, and no participant had white-coat hypertension [37], whereas in the study by Ahmed et al. [29], the relevant proportions were 58 and $3 \%$, respectively. Our study expands these findings by confirming the high rates of masked hypertension in a considerably larger cohort and at 2 different BP thresholds. The reasons for this phenomenon in KTRs are currently unknown: familiarization with the transplant clinic environment and the doctors and nurses involved in the patient care, increased time for relaxation, or the relatively young age and active lifestyle of KTRs in relation to other patient categories may be all involved. One major reason, however, is rather the high prevalence of nocturnal hypertension in KTRs. Previous studies have showed high rates of nondipping and reverse-dipping pattern in these individuals, with the majority of patients classified as hypertensives due to increased nighttime BP [12-14]; furthermore, in the study by Ahmed et al. [29], in more than half of the patients diagnosed with masked hypertension, the cause was isolated nocturnal hypertension. This alarmingly high rate and the associations of masked hypertension with outcomes [38] is another strong argument calling for wider use of ABPM in KTRs [39].

In addition to the above, several studies in the general population [40] and CKD patients [41] have shown poor diagnostic accuracy of office BP in predicting ambulatory BP levels. With regard to KTRs, a study by Mallamaci et al. [42], comparing routinely measured office BP with 24-h ABPM, found generally poor agreement between office $\mathrm{BP}$ and $\mathrm{ABP}$ readings, with misclassification of $\mathrm{BP}$ control status at $37 \%$ of visits. Our study is the first study evaluating in parallel the diagnostic performance of 2 different office BP thresholds in KTRs. Our findings clearly suggest that office $\mathrm{BP}$ has a suboptimal sensitivity and specificity for diagnosing ambulatory BP. In ROC analy- sis, the AUCs of office SBP/DBP with the ESC/ESH definition for the diagnosis of high ambulatory BP were 0.659 and 0.578, whereas the relevant AUCs with the ACC/ AHA definition were only slightly better, that is, 0.695 and 0.679 , indicating a poor overall performance.

This study has strengths and limitations. It included a relatively large population of KTRs, applied a strict methodology of standardized office and 24-h ABPM readings, and evaluated simultaneously a number of questions, including the rates of prevalence, treatment and control, of hypertension, the $\mathrm{BP}$ phenotypes and the diagnostic performance of 2 distinct office BP thresholds against ambulatory $\mathrm{BP}$. One limitation is the fact that the "corresponding" office and ambulatory BP thresholds used herein, deriving from a table of equivalent $\mathrm{BP}$ values among standardized office and 24-h ABPM values from the 2017 ACC/AHA guideline, were established using an outcome-based approach that determines the BP thresholds associated with similar long-term outcomes in study populations, as there are not randomized studies assessing the effects of treatment to specific ambulatory BP goals [43]. Another potential limitation is that this is a singlecenter study in mainly Caucasian KTRs, and the results may not be extrapolated to patients of different ethnicity. Finally, the cross-sectional design does not enable us to assess long-term associations with renal and cardiovascular outcomes.

In conclusion, this study clearly shows that prevalence of hypertension in KTRs is high with the use of office BP and even higher with the use of ABPM. Conversely, the rates of $\mathrm{BP}$ control among hypertensive patients are significantly lower when ABPM is used instead of office BP, independently of the threshold studied. With the use of the recently recommended 130/80 office BP threshold and the corresponding 125/75 mm Hg ABPM threshold, $\mathrm{BP}$ control rates are disappointing. Misclassification of patients by office BP is the rule in KTRs, a fact mostly due to an alarmingly high rate of masked hypertension. At both the ESC/ESH and ACC/AHA thresholds, the diagnostic accuracy of high office BP to identify elevated ambulatory BP was poor. The above observations call for a wider use of ABPM in the diagnosis and management of hypertension in KTRs.

\section{Statement of Ethics}

The study protocol was approved by the Institutional Review Board of Laiko General Hospital. All evaluations were performed according to the Declaration of Helsinki (2013 Amendment). 


\section{Conflict of Interest Statement}

Authors wish to state that they do not have a conflict of interest regarding this study.

\section{Funding Sources}

This study was not supported by any source and represents an original effort of the authors.

\section{Author Contributions}

Research idea and study design: P.S. and S.M.; data acquisition: M.K. and E.X.; statistical analysis: M.T. and M.A.; data analysis and interpretation: P.S., M.K., and S.M.; manuscript drafting: M.K. and M.T.; supervision or mentorship: I.B.

\section{References}

1 Mills KT, Xu Y, Zhang W, Bundy JD, Chen CS, Kelly TN, et al. A systematic analysis of worldwide population-based data on the global burden of chronic kidney disease in 2010. Kidney Int. 2015;88(5):950-7.

2 Sarafidis PA, Li S, Chen SC, Collins AJ, Brown WW, Klag MJ, et al. Hypertension awareness, treatment, and control in chronic kidney disease. Am J Med. 2008;121(4):332-40.

3 Rangaswami J, Mathew RO, Parasuraman R, Tantisattamo E, Lubetzky M, Rao S, et al. Cardiovascular disease in the kidney transplant recipient: epidemiology, diagnosis and management strategies. Nephrol Dial Transplant. 2019;34(5):760-73.

4 Pilmore H, Dent H, Chang S, McDonald SP, Chadban SJ. Reduction in cardiovascular death after kidney transplantation. Transplantation. 2010;89(7):851-7.

5 Awan AA, Niu J, Pan JS, Erickson KF, Mandayam S, Winkelmayer WC, et al. Trends in the causes of death among kidney transplant recipients in the United States (1996-2014). Am J Nephrol. 2018;48(6):472-81.

6 Ponticelli C, Cucchiari D, Graziani G. Hypertension in kidney transplant recipients. Transpl Int. 2011;24(6):523-33.

7 Opelz G, Döhler B; Collaborative Transplant Study. Improved long-term outcomes after renal transplantation associated with blood pressure control. Am J Transplant. 2005; 5(11):2725-31

8 Parati G, Ochoa JE, Bilo G, Agarwal R, Covic A, Dekker FW, et al. Hypertension in chronic kidney disease part 1: out-of-office blood pressure monitoring: methods, thresholds, and patterns. Hypertension. 2016;67(6):1093-101.

9 Parati G, Ochoa JE, Bilo G, Agarwal R, Covic A, Dekker FW, et al. Hypertension in chronic kidney disease part 2: role of ambulatory and home blood pressure monitoring for assessing alterations in blood pressure variability and blood pressure profiles. Hypertension. 2016;67(6):1102-10.

10 Tiryaki O, Usalan C, Kul S, Tarakcioglu M, Sucu M, Yildiz F, et al. Urinary angiotensinogen level is increased in renal transplant recipients with masked hypertension and is correlated with left ventricular mass index and albuminuria in these patients. Clin Transplant. 2018;32(9):e13375.
11 Kayrak M, Gul EE, Kaya C, Solak Y, Turkmen $\mathrm{K}$, Yazici R, et al. Masked hypertension in renal transplant recipients. Blood Press. 2014; 23(1):47-53.

12 Mallamaci F, Tripepi R, Leonardis D, Mafrica A, Versace MC, Provenzano F, et al. Nocturnal hypertension and altered night-day BP profile and atherosclerosis in renal transplant patients. Transplantation. 2016;100(10):2211-8.

13 Wadei HM, Amer H, Griffin MD, Taler SJ, Stegall MD, Textor SC. Abnormal circadian blood pressure pattern 1-year after kidney transplantation is associated with subsequent lower glomerular filtration rate in recipients without rejection. J Am Soc Hypertens. 2011; 5(1):39-47.

14 Ibernon M, Moreso F, Sarrias X, Sarrias M, Grinyó JM, Fernandez-Real JM, et al. Reverse dipper pattern of blood pressure at 3 months is associated with inflammation and outcome after renal transplantation. Nephrol Dial Transplant. 2012;27(5):2089-95.

15 Castillo-Rodriguez E, Fernandez-Fernandez B, Alegre-Bellassai R, Kanbay M, Ortiz A. The chaos of hypertension guidelines for chronic kidney disease patients. Clin Kidney J. 2019; 12(6):771-7.

16 James PA, Oparil S, Carter BL, Cushman WC, Dennison-Himmelfarb C, Handler J, et al. 2014 evidence-based guideline for the management of high blood pressure in adults: report from the panel members appointed to the eighth joint national committee (JNC 8). JAMA. 2014;311(5):507-20.

17 Williams B, Mancia G, Spiering W, Agabiti Rosei E, Azizi M, Burnier M, et al. 2018 ESC/ ESH Guidelines for the management of arterial hypertension: the task force for the management of arterial hypertension of the European Society of Cardiology and the European Society of Hypertension: the task force for the management of arterial hypertension of the European Society of Cardiology and the European Society of Hypertension. J Hypertens. 2018;36(10):1953-2041.

18 Whelton PK, Carey RM, Aronow WS, Casey DEJr, Collins KJ, Dennison Himmelfarb C, et al. 2017 ACC/AHA/AAPA/ABC/ACPM/ AGS/APhA/ASH/ASPC/NMA/PCNA guideline for the prevention, detection, evaluation, and management of high blood pressure in adults: a report of the American college of cardiology/American heart association task force on clinical practice guidelines. J Am Coll Cardiol. 2018;71(19):e127-248.

19 Kidney Disease: Improving Global Outcomes (KDIGO) Blood Pressure Work Group. KDIGO 2021 clinical practice guideline for the management of blood pressure in chronic kidney disease. Kidney Int. 2021;99(3S):S1-87.

20 Franssen PM, Imholz BP. Evaluation of the mobil-O-graph new generation ABPM device using the ESH criteria. Blood Press Monit. 2010;15(4):229-31.

21 Wei W, Tölle M, Zidek W, van der Giet M. Validation of the mobil-O-graph: 24 h-blood pressure measurement device. Blood Press Monit. 2010;15(4):225-8.

22 Sarafidis PA, Lazaridis AA, Imprialos KP, Georgianos PI, Avranas KA, Protogerou AD, et al. A comparison study of brachial blood pressure recorded with Spacelabs 90217A and mobil-O-graph NG devices under static and ambulatory conditions. J Hum Hypertens. 2016;30(12):742-9.

23 Parati G, Stergiou G, O'Brien E, Asmar R, Beilin L, Bilo G, et al. European society of hypertension practice guidelines for ambulatory blood pressure monitoring. J Hypertens. 2014;32(7):1359-66.

$24 \mathrm{McHugh}$ ML. Interrater reliability: the kappa statistic. Biochem Med. 2012;22(3):276-82.

25 Sarafidis PA, Ruilope LM. Aggressive blood pressure reduction and renin-angiotensin system blockade in chronic kidney disease: time for re-evaluation? Kidney Int. 2014; 85(3):536-46.

26 Sarafidis PA, Lazaridis AA, Ruiz-Hurtado G, Ruilope LM. Blood pressure reduction in diabetes: lessons from ACCORD, SPRINT and EMPA-REG OUTCOME. Nat Rev Endocrinol. 2017;13(6):365-74.

27 Sarafidis P, Loutradis C, Ortiz A, Ruilope LM. Blood pressure targets in patients with chronic kidney disease: MDRD and AASK now confirming SPRINT. Clin Kidney J. 2020; 13(3):287-90.

28 Firat A, Kaya B, Balal M, Paydas S, Akilli R. Relationship between peripheral-central blood pressure and cardiac-renal damage in kidney transplant recipients. Exp Clin Transplant. 2019;17(Suppl 1):188-94. 
29 Ahmed J, Ozorio V, Farrant M, Van Der Merwe W. Ambulatory vs office blood pressure monitoring in renal transplant recipients. J Clin Hypertens. 2015;17(1):46-50.

30 Paoletti E, Gherzi M, Amidone M, Massarino F, Cannella G. Association of arterial hypertension with renal target organ damage in kidney transplant recipients: the predictive role of ambulatory blood pressure monitoring. Transplantation. 2009;87(12):1864-9.

31 Pisano A, Bolignano D, Mallamaci F, D’Arrigo G, Halimi JM, Persu A, et al. Comparative effectiveness of different antihypertensive agents in kidney transplantation: a systematic review and meta-analysis. Nephrol Dial Transplant. 2020;35:878-87.

32 Halimi JM, Ortiz A, Sarafidis P, Mallamaci F, Wuerzner G, Pisano A, et al. Hypertension in kidney transplantation: a consensus statement of the "Hypertension and the kidney" working group of the European Society of Hypertension (ESH). J Hypertens. 2021;39(8): 1513-1521.

33 Kolonko A, Bartmańska M, Słabiak-Błaż N, Kuczera P, Kujawa-Szewieczek A, Ficek R, et al. Arterial stiffness but not endothelial dysfunction is associated with multidrug antihypertensive therapy and nondipper blood pressure pattern in kidney transplant recipients. Medicine. 2018;97(36):e11870.
34 Czyżewski Ł, Wyzgał J, Kołek A. Evaluation of selected risk factors of cardiovascular diseases among patients after kidney transplantation, with particular focus on the role of 24hour automatic blood pressure measurement in the diagnosis of hypertension: an introductory report. Ann Transplant. 2014;19:188-98.

35 Gorostidi M, Sarafidis PA, de la Sierra A, Segura J, de la Cruz JJ, Banegas JR, et al. Differences between office and 24-hour blood pressure control in hypertensive patients with CKD: a 5,693-patient cross-sectional analysis from Spain. Am J Kidney Dis. 2013;62(2): 285-94.

36 Sarafidis PA, Mallamaci F, Loutradis C, Ekart $\mathrm{R}$, Torino C, Karpetas A, et al. Prevalence and control of hypertension by 48 -h ambulatory blood pressure monitoring in haemodialysis patients: a study by the European cardiovascular and renal medicine (EURECA-m) working group of the ERA-EDTA. Nephrol Dial Transplant. 2019;34(9):1542-8.

37 Azancot MA, Ramos N, Moreso FJ, Ibernon $\mathrm{M}$, Espinel E, Torres IB, et al. Hypertension in chronic kidney disease: the influence of renal transplantation. Transplantation. 2014;98(5): 537-42.

38 Banegas JR, Ruilope LM, de la Sierra A, Vinyoles E, Gorostidi M, de la Cruz JJ, et al. Relationship between clinic and ambulatory blood-pressure measurements and mortality. N Engl J Med. 2018;378(16):1509-20.
39 Halimi JM, Persu A, Sarafidis PA, Burnier M, Abramowicz D, Sautenet B, et al. Optimizing hypertension management in renal transplantation: a call to action. J Hypertens. 2017; 35(12):2335-8.

40 Hodgkinson J, Mant J, Martin U, Guo B, Hobbs FD, Deeks JJ, et al. Relative effectiveness of clinic and home blood pressure monitoring compared with ambulatory blood pressure monitoring in diagnosis of hypertension: systematic review. BMJ. 2011;342:d3621.

41 Agarwal R, Metiku T, Tegegne GG, Light RP, Bunaye Z, Bekele DM, et al. Diagnosing hypertension by intradialytic blood pressure recordings. Clin J Am Soc Nephrol. 2008;3(5): 1364-72.

42 Mallamaci F, Tripepi R, D’Arrigo G, Porto G, Versace MC, Marino C, et al. Long-term blood pressure monitoring by office and $24-\mathrm{h}$ ambulatory blood pressure in renal transplant patients: a longitudinal study. Nephrol Dial Transplant. 2019;34(9):1558-64.

43 Muntner P, Carey RM, Jamerson K, Wright JT, Whelton PK. Rationale for ambulatory and home blood pressure monitoring thresholds in the 2017 American college of cardiology/American heart association guideline. Hypertension. 2019;73(1):33-8. 